\title{
Pitfalls in the Economic Analysis of Aging
}

\author{
Hendrik P. van Dalen, Research Centre for Economic Policy \\ (OCFEB), Erasmus University Rotterdam, Tinbergen \\ Rotterdam-Amsterdam Centre for Economics (TRACE)
}

In this paper we examine a number of pitfalls that one encounters in the economic calculus of the consequences of aging populations. The main pitfalls of viewing the demographic future lie in assumptions concerning (1) the (ultimate) stationarity of population growth and the assumptions underlying those of the "theory" of demographic transition, (2) the exogeneity of factor prices and the state of technology, (3) the neglect of implicit delayedpayment contracts within firms in which younger workers implicitly pay for the wages of older workers, and (4) the time inconsistency of intergenerational transfer schemes in general.

\section{INTRODUCTION}

With the emergence of aging economies, economists, sociologists, and demographers are becoming concerned with the sustainability of the welfare state - a welfare state that has been expanding ever since the Second World War. The expansion seems to have been stopped in its growth by the policymakers of a supply-side persuasion in the 1980s. The general feeling is that the welfare state has reached its limits, and with a view to the aging of populations, it is felt that drastic reforms are needed. A number of studies have appeared that have tried to assess the future of the welfare state in an aging society. ${ }^{1}$ As with all scientific work, the authors of these

\footnotetext{
${ }^{1}$ See, e.g., Heller, Hemming, and Kohnert (1986), Halter and Hemming (1987), OECD (1988), Hagemann and Nicoletti (1989), Auerbach et al. (1989), Masson and Tryon (1990), and Cutler et al. (1990).

Address correspondence to Prof. Hendrik P. van Dalen, Research Centre for Economic Policy (OCFEB), Erasmus University Rotterdam, P. O. Box 1738, 3000 DR Rotterdam, The Netherlands.

Research was carried out with the support of the Netherlands Organization for Scientific Research (NWO), research grants \#18.509 and \#450-226-026.

Received December 1994; final draft accepted May 1995.
} 
studies had to use Occam's razor to make a distinction between important and unimportant elements of aging. However, leaving out unimportant aspects of a problem is a personal choice that may be open to debate, especially when the omission of an element changes policy conclusions radically.

In order to weed out the important missing elements in a number of studies, I have summed up the most important pitfalls that one may encounter in the economic analysis of aging economies. In the process of modeling aging economies, one tends to abstract from this phenomenon in an inadequate manner. As with all of such shortcomings, one can learn two lessons from them. The first lesson amounts, of course, to the warning to be cautious in formulating policy implications too hastily. One should qualify one's conclusions by paying attention to the pitfall in question. The second lesson is perhaps more challenging, namely, one starts incorporating the missing element in economic theory. This second lesson applies only to some of the listed pitfalls because the other shortcomings are true pitfalls: They refer to the unsound application of economic theory to otherwise sound practical policy problems. For those cases, one should develop the art of economics - an art that both requires knowledge of institutions and of social, political, and historical phenomena and requires the ability to use available data in a reasonable way in discussing real-world economic issues (compare Colander, 1992).

The first pitfall that we will deal with concerns the alleged constancy of population growth and the stability of age structures in the long run. It is a well-established convention in these studies to assume that economies return to some steady-state population growth rate. Demographic stability is refuted by demographic history. Key demographic variables, such as the retirement age, life expectancy, and the fertility and mortality rates, are uncertain variables and to some extent endogenous. The appropriate response would be to recognize the non-stationary character of demography and to view demographic and economic variables simultaneously.

The second pitfall is related to the exogeneity of the state of technology and the relative factor prices of capital, labor, and natural resources. Introducing exogenous and constant prices is in most cases a matter of convenience and technical simplicity. Developing a model of price formation is bound to make dynamic general equilibrium models intractable, but for policy evaluation endoge- 
nous prices and technology $y^{2}$ are of prime importance to assess the welfare implications of aging populations. Furthermore, relative factor prices are, more than demographic variables, prone to uncertainty.

Pitfall number three concerns the inherent time inconsistency tied to the pay-as-you-go (PAYG) system of financing social security and, in some cases, private pension plans (namely, "final pay" arrangements). Sustainability of PAYG schemes is not credible because it introduces a conflict between the government in charge of the social security system and the individual citizens having to pay for this system. This section, in short, treats the political side of aging populations, although we are aware that the politics of aging are more far-reaching. The pitfall many economists or policymakers are likely to overlook is that one analyzes future social security systems as if the government is committed to some designed tax-transfer program for a specific planning horizon. As will be shown, a social security system is inherently time-inconsistent, inducing a government to renege its original plans at some point in time, arising mainly from an externality in decision making, an externality that is lost under conditions of decentralization and the absence of a commitment technology (like a law).

The fourth and last pitfall is the much-neglected intergenerational transfer scheme that is used inside organizations. As empirical evidence presented by Eggink, Hop, and van Praag (1993) and Kotlikoff and Gokhale (1992) shows, young workers implicitly subsidize older workers by receiving a wage income below their marginal productivity, and older workers receive an income well in excess of their marginal productivity. The pitfall one falls into in forecasting future real wage rates is to base those rates on the contemporaneous marginal productivity of labor instead of recognizing the age-related divergence between productivity and payment. Neglect of the implicit pay-as-you-go scheme inside firms may make the future of firms in an aging society seem overly optimistic and forecasts of wage rates (and subsequent pension liabilities) erroneous.

The chronology of this paper is in accordance with the abovementioned list of pitfalls. In Section 6, I will summarize the main conclusions and discuss some additional aspects of aging that fall outside the scope of this paper but are nonetheless relevant for the economic policy analysis of aging.

\footnotetext{
${ }^{2}$ See Alogoskoufis and van der Ploeg (1990).
} 


\section{PITFALL I: DEMOGRAPHIC STABILITY AND CONSTANCY}

The mechanism that drives many models of aging is the general dependency ratio of retired or inactive population to that of the active or working population. There is much confusion about whether aging has a positive or negative impact on economic welfare. The confusion arises to some extent because economists use different welfare functions or different welfare parameters to evaluate economic outcomes, but the main root of confusion is to be found in the object of study: Some economists focus on the consequences for government policy and others on the consequences for the private sector. Because the government finances the bulk of its output and transfers in an unfunded manner, the government will be heavily influenced by the change in population structure. An aging population implies in general a higher per capita tax burden, not only because of the changing ratio of active and inactive citizens, but also because the claim on public goods and services increases with age.

For the private sector the consequences are less clear-cut, although the general feeling is that an aging of the population and a slowdown of the population growth rate are beneficial to intergenerational welfare (see Cutler et al., 1990). In this section, I first want to review some of the demographic assumptions that are implicitly or explicitly used in forecasting the economic consequences of aging. The analysis will be partial for expository reasons. Second, I will pay attention to the pitfalls that one encounters in viewing the dynamics of aging. False pictures about the length and speed of aging may be drawn if one does not pay attention to private decision making on fertility, schooling, retirement, and health investments.

A central tenet in studying aging economies is that the population growth rate eventually settles down to a constant and stable growth rate. This is to a large extent a fallacious reflection of reality because population growth has a natural tendency to fluctuate, whether this arises from structural uncertainty or from intentional household decision making. The stochastic behavior of demography is perhaps best illustrated by examining the two main underlying forces behind the population growth rate over time: the crude birth rate (CBR) and the crude death rate (CDR), per 1000 persons. Figures 1a and $1 \mathrm{~d}$ show the development of both variables over time for the population of England and Wales and for that of the Netherlands, respectively. As one can see, the CBR and the CDR seem to move in 


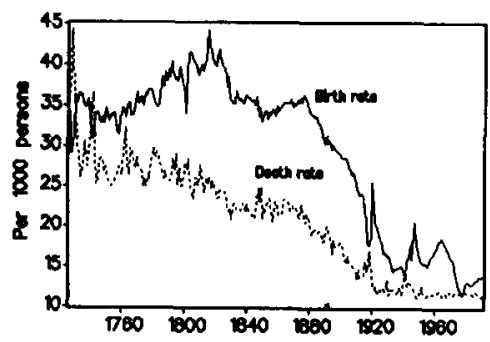

(a)

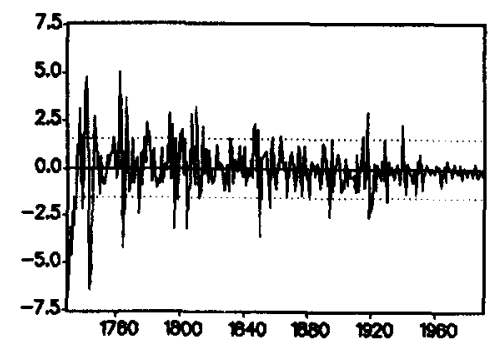

(c)

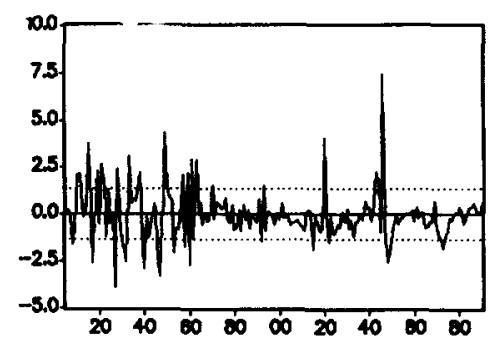

(e)

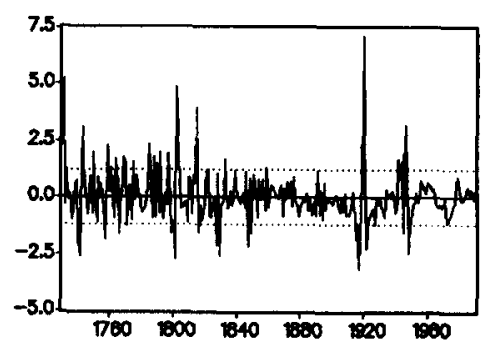

(b)

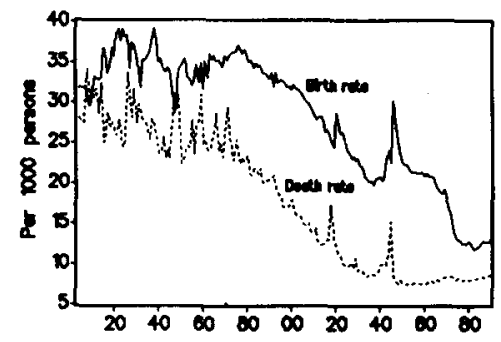

(d)

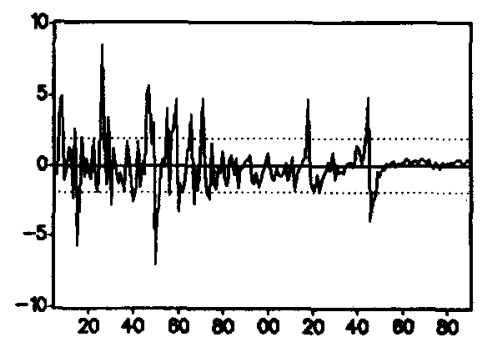

(f)

Figure 1(a) CDR and CBR, England and Wales, 1727-1990. (b) Fertility uncertainty, England and Wales. (c) Mortality uncertainty, England and Wales. (d) CBR and CDR, the Netherlands, 1805-1990. (e) Fertility uncertainty, the Netherlands. (f) Mortality uncertainty, the Netherlands.

line. However, both variables have slightly different time-series properties. For example, the uncertainty surrounding mortality and fertility diverge, especially in the last 20 years $^{3}$ (see Figures $1 \mathrm{~b}$

${ }^{3}$ The Figures 1b, 1c, 1e, and $1 \mathrm{f}$ are constructed by estimating an ARMA(1,1) process for the CDR and the CBR. The uncertainty in both graphs is in fact the residual of fitted and actual time series. 
Table 1A:: Unit Root Tests for Mortality and Fertility

\begin{tabular}{ccccc}
\hline Series and country & Time span & Lag length* & $\begin{array}{c}\text { ADF-t statistic } \\
\text { with constant }\end{array}$ & $\begin{array}{c}\text { ADF-t statistic } \\
\text { with constant and } \\
\text { trend term }\end{array}$ \\
\hline Crude birth rate & $1727-1920$ & 5 & 0.120 & 0.752 \\
England and Wales & $1920-1990$ & 4 & -1.685 & -2.161 \\
& $1727-1990$ & 6 & 0.200 & -1.594 \\
The Netherlands & $1803-1946$ & 4 & -1.201 & -2.740 \\
& $1946-1990$ & 3 & -0.927 & $-3.850^{* *}$ \\
Crude death rate & $1803-1990$ & 5 & 0.281 & $-3.180^{*}$ \\
England and Wales & $1727-1920$ & 5 & -1.403 & $-4.351^{* *}$ \\
& $1920-1990$ & 4 & $-5.436^{* * *}$ & $-6.039^{* * *}$ \\
The Netherlands & $1727-1990$ & 6 & -1.182 & $-3.421^{*}$ \\
& $1803-1946$ & 4 & -0.850 & -2.593 \\
& $1946-1990$ & 3 & $-14.924^{* * *}$ & $-24.440^{* * *}$ \\
& $1803-1990$ & 5 & -1.126 & -2.016 \\
\hline
\end{tabular}
1984.

a The lag length is roughly equal to the third root of the sample size (see Said and Dickey,

b Augmented Dickey-Fulller test statistics.

* Statistically significant at $\mathbf{0 . 1 0}$ level, based on MacKinnon critical $t$-values.

** Statistically significant at 0.05 level.

*** Statistically significant at 0.01 level.

through 1f). The predictability of the CDR has increased in the last 20 years, whereas the predictability of the CBR remains unaltered. This is, however, a superficial deduction about the time-series properties of these two variables.

If one wants to be more confident about the future be of demographic variables, one should have a firm grasp of demographic history and examine statistically whether fertility and mortality are stationary for subsamples of history. We can test the stationarity of fertility and mortality time series more formally by means of unit root tests. ${ }^{4}$ Table 1 shows the stationarity tests that reveal whether the CDR and the CBR are stationary. Unit root tests show that the CBR cannot be described as a stationary variable over time. Only for the case of the CDR for the subsample 1920-90 for England and Wales can one safely say that it is stationary. The

\footnotetext{
${ }^{4}$ For an introduction on unit roots and cointegration, see Stewart (1991).
} 
augmented Dickey-Fuller $t$-statistics are statistically significant at 1-percent level. To check whether the English demographic history is an exceptional case, I have run the same tests on Dutch data for the sample period 1803-1990. The conclusions are similar to those for England and Wales. Only for the subsample 1946-90 can one detect stationarity in the CDR at the 1-percent significance level.

In the theory of demographic transition both the death rate and the birth rate are supposed to be interrelated. The postulated change is from near equality of birth and death rates at high levels in a traditional society to near equality at low levels in a highly modernized society (Coale, 1989). A priori one would expect that in the modern-day societies the interdependency between fertility and mortality is no longer valid because the need for having children seems to have diminished with the advance of the modern welfare state. The old-age-security hypothesis of children functioning as a capital good in old age seems to have ended in the first half of the twentieth century, an era that is marked by the emergence of government-provided social security. Another feature of demographic transition is that the decline in mortality normally preceded the decline in fertility. We can test the propositions of demographic transition more formally by employing the Engle-Granger cointegration tests.

Table 2 shows for the English and Welsh population that from 1727 to 1990 the relationship between the birth rate and the death rate is not valid at standard significance levels. Lagging the mortality rate by 10 years (and longer time lags, such as 25 years) does not change this conclusion. For the Netherlands this relationship only seems to exist prior to the Second World War, but only at the 5-percent significance level. The non-existence or weak existence of the relationship between fertility and mortality makes it all the more important to view both elements more carefully in predicting future demographic developments.

Summing up, using a constant or stationary demographic state as a point of departure for analyzing aging economies is a pitfall if we look at the statistical properties of demographic history. However, economists are merely human, and using an unrealistic premise is not that serious if the economic content of aging surpasses the demographic content of aging in terms of importance. However, if we stick to the assumption that the fluctuations in population growth rate will peter out and become constant at some point in time, we are still left with another pitfall, namely the endogeneity of demography. The main determinants driving the dependency 
Table 2: Engle-Granger Cointegration Tests Between Mortality and Fertility

\begin{tabular}{|c|c|c|c|c|c|c|}
\hline \multirow[b]{2}{*}{ Country } & \multirow{2}{*}{$\begin{array}{l}\text { Time } \\
\text { span }\end{array}$} & \multirow{2}{*}{$\begin{array}{c}\text { Lag } \\
\text { length" }\end{array}$} & \multicolumn{2}{|c|}{$\begin{array}{l}\text { ADF }^{\text {-statistic with }} \\
\text { lag mortalityd: }\end{array}$} & \multicolumn{2}{|c|}{$\begin{array}{l}\text { ADFc-statistic with } \\
\text { lag mortalityd: }\end{array}$} \\
\hline & & & $\mathbf{0}$ & 10 & 0 & 10 \\
\hline \multirow[t]{3}{*}{ England and Wales } & $1727-1920$ & 5 & -1.839 & -1.859 & -1.623 & -1.735 \\
\hline & $1920-1990$ & 4 & -2.181 & -2.701 & -2.909 & -2.668 \\
\hline & $1727-1990$ & 6 & -2.240 & -2.665 & -1.860 & -2.459 \\
\hline \multirow[t]{3}{*}{ The Netherlands } & $1803-1946$ & 4 & $-3.374^{* *}$ & $-3.590 * *$ & $-3.587^{*}$ & -3.386 \\
\hline & $1946-1990$ & 3 & -1.982 & -1.215 & -1.534 & -1.278 \\
\hline & $1803-1990$ & 5 & -2.159 & -2.466 & -2.086 & -2.444 \\
\hline
\end{tabular}

a The lag length is roughly equal to the third root of the sample size (see Said andDickey, 1984.

b Augmented Dickey-Fuller test statistics for cointegration test with a constant term.

' Augmented Dickey-Fuller test statistics for cointegration test with a constant and a trend term.

${ }^{d}$ The mortality rate is lagged in order to test for the hypothesis that a fertility decline follows a mortality decline with some time lag. A time lag of, e.g., 25 years did not change our conclusions.

* Statistically significant at $\mathbf{0 . 1 0}$ level based on MacKinnon critical $t$-values.

** Statistically significant at 0.05 level.

ratios are demographic and economic parameters such as the retirement age, the average life expectancy, the number of years of formal schooling, and the birth rate. With respect to each of these variables applied economists and demographers alike treat them as natural constants, whereas each and every one of these variables are subject to choice, whether directly or, in the case of life expectancy and the birth rate, indirectly. The date of retirement from the labor force is a choice variable (see OECD, 1992, and Henkens and Siegers, 1991), and given the fact that individuals have different life expectancies and working careers, they are inclined to choose different dates of retirement. As it turns out, low-income individuals have on average a lower life expectancy than high-income individuals, a fact that is to a large extent caused by different life-styles and diverging health investments. The different planning horizons that are a result of these factors naturally induce one to take different retirement decisions (see Lazear, 1986). Low-income individuals retire on average earlier than high-income individuals. Furthermore, the individual reactions are reinforced by the economic (dis)incentives that arise on account of the intergenerational public transfer schemes that are applicable in most OECD countries. The 
PAYG schemes formalized in public pension systems do not stimulate savings and work effort. The reason why is quite simple: Under conditions of dynamic efficiency, a PAYG schedule implies a decrease in lifetime income. To rephrase this: The average consumer pays more in taxes than he will receive in benefits. Of course this applies to a homogenous population. If there are income differences across individuals, this may cause different incentives to save and work across income groups.

Because of these intragenerational and intergenerational transfers, it is of importance to observe the various dependency ratios. The two most-cited dependency ratios relate the population of oldaged and the general dependent population (old aged and children) to the potential work force. To see this more clearly we can write these two ratios down explicitly. The total population, $N(t)$, at time $t$ ), can be split up into three different age categories: the children and adolescents $\left(N_{C}\right)$, the potential work force $\left(N_{W}\right)$ and the old and retired $\left(N_{R}\right)$. In order to write down the size of the total population and its subparts, we have to know the average life expectancy $(T)$, the age at which one starts working $(H)$, the retirement age $(R)$, and the population growth rate $(n)$. The population is assumed to be stable, growing exponentially at the rate $n$. Births per unit of time, $B(t)$, are given by: $B(t)=B(0) e^{n t}$. If we normalize the initial birth cohort, $B(0)$, to 1 we can write down the different populations:

$$
N_{t}=N_{C t}+N_{W t}+N_{R t}=\int_{t-T}^{t} e^{n s} d s=\frac{1-e^{-n T}}{n} e^{n t}
$$

where:

$$
\begin{aligned}
& N_{C t}=\int_{t-H}^{t} e^{n s} d s=\frac{1-e^{-n H}}{n} e^{n t} \\
& N_{W t}=\int_{t-R}^{t-H} e^{n s} d s=\frac{e^{-n H}-e^{-n R}}{n} e^{n t} \\
& N_{R t}=\int_{t-T}^{t-R} e^{n s} d s=\frac{e^{-n R}-e^{-n T}}{n} e^{n t}
\end{aligned}
$$

In the day-to-day practice of the policymaker, the simple dependency ratio of the old to potential work force $\left(\eta=N_{R} / N_{W}\right)$ is often used. Because the majority of public pension programs are financed on a PAYG basis, one can also interpret $\eta$ as the lump sum tax the work force has to pay to the retired population.

If one wants more general dependency ratios, one should also include the other population group that depends on the income 
Table 3: Stable Population Dependency Ratios

\begin{tabular}{lcc}
\hline & $\eta$ & $\varphi$ \\
\hline Benchmark $^{\mathrm{a}}$ & $16.5 \%$ & $61.3 \%$ \\
$H=18$ & $17.4 \%$ & $70.0 \%$ \\
$H=20$ & $18.3 \%$ & $79.4 \%$ \\
$R=67$ & $12.9 \%$ & $56.4 \%$ \\
$R=63$ & $20.3 \%$ & $66.6 \%$ \\
$T=78$ & $19.3 \%$ & $64.1 \%$ \\
$T=80$ & $22.0 \%$ & $66.8 \%$ \\
$n=0 \%$ & $22.4 \%$ & $55.1 \%$ \\
$n=-1 \%$ & $30.0 \%$ & $53.4 \%$ \\
\hline
\end{tabular}

a Calculations based on the parameters: $H=16, R=65, T=76, n=1 \%$.

from the adults, namely the children and adolescents, giving the following ratio: $\varphi=\left(N_{R}+N_{C}\right) / N_{W}$. Writing these ratios down:

$$
\begin{gathered}
\eta=\frac{e^{-n R}-e^{-n T}}{e^{-n H}-e^{-n R}} \\
\varphi=\frac{\left(e^{-n R}-e^{-n T}+1-e^{-n H}\right)}{\left(e^{-n H}-e^{-n R}\right)}
\end{gathered}
$$

Table 3 gives some numerical examples of dependency ratios for stable population structures. As one can deduce from Table 3, a decrease in the birth rate has a large effect on the simple dependency ratio, $\eta$. The general dependency ratio $(\varphi)$ behaves in more or less the same direction, with exception of the effect of a population decline: Population decline alleviates the work force to some extent, whereas in the case of the simple dependency ratio, a population decline increases the burden on the work force.

These stable dependency ratios provide us with some background to evaluate the historical development of dependency ratios for the U.K. population for the period 1900-90. The steady increase in old-age dependency ratio $(\eta)$ for the United Kingdom as shown in Figure 2 is to some extent explained by a fertility decline. However, the increase in $\eta$ cannot be caused by a fertility decline only; the increase in longevity is also a plausible aging factor.

Increased longevity has two effects on the demography of a country that need to be distinguished, namely (1) a fall in the mortality rate, $d$, will lead to an increase in the aggregate population growth rate, and (2) because mortality is not evenly distributed over the 


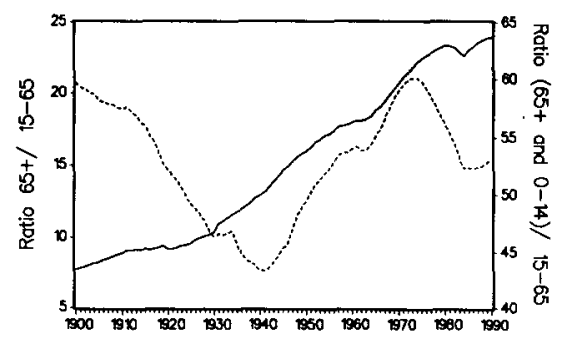

Figure 2. Dependency ratios, U.K., 1990-1990.

Simple dependency ratio . . . . General dependency ratio

different age groups, a fall in mortality will lead to an increase in the number of retired and old aged. As Figure 3 shows, the improved living conditions in England and Wales have led to a considerable fall in the infant mortality rate and old-age mortality rate. The role of infant mortality is nowadays negligible, thereby giving more importance to the role of old-age mortality.

So far we have only discussed stable populations, which in the demographic sense of the term means that the age-specific rate of fertility and mortality and its (normalized) age distribution are all constant over time. From an economic and demographic point of view, it would be desirable to talk about the consequences of non-stable populations. Only a few economists ${ }^{5}$ have looked at the questions of non-stationary population growth, perhaps because the dynamics of non-stationary population growth are far less transparent than its stationary counterpart. In the remainder of this section I will elaborate on the economic consequences of a

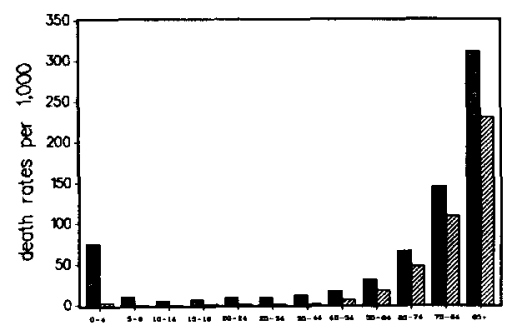

Figure 3. Mortality rate per age-group, 1840 vs. 1980 .

$\square$ death rate, males, $1840 \square$ death rate, males, 1980

${ }^{5}$ See Merton (1975) and Van Imhoff (1989). 
population decline, ${ }^{6}$ as caused by a drop in fertility $(b)$, and increased longevity, as caused by a drop in the mortality rate $(d)$, and discuss the various pitfalls that lie in wait behind these changes. The effect of migration is left out of the analysis because of the plethora of assumptions that accompany this part of demography. ${ }^{7}$

To keep things simple I will restrict attention to a population that consists of workers and retirees. Suppose that the population grows steadily until time $t_{0}$. Assume furthermore that this switching point lies far into the future (i.e., $t_{0}>T$ ) so that a steady-state population distribution has been achieved at time $t_{0}$. After $t_{0}$ the population growth rate drops to $n^{\prime}<n$ and remains there permanently. The population growth decline is caused by a drop in fertility: $n^{\prime}=b^{\prime}-d$ and $n=b-d$, where $b^{\prime}<b$. Under these assumptions the number of people born at time $t$ will be:

$$
N_{t}=\left\{\begin{array}{l}
N_{0} e^{n t} \text { for } t \leq t_{0} \\
N_{t} e^{r\left(t-t_{0}\right.}=N_{0} e^{n_{0}} e^{r^{\prime\left(t-t_{0}\right)} \text { for } t>t_{0}}
\end{array}\right.
$$

To analyze the implications of a population decline, one can make the analysis more transparent by dividing the transition period into three intervals. These three intervals mark the manner in which the relatively large cohorts affect the population pyramid. At first one will encounter an aging labor force, then one will experience a boom in retirement, and in a third phase one will return to a new steady state that is marked by an older population structure.

\section{A. The Interval $t \in\left(t_{0}, t_{0}+R\right)$ : The Aging Labor Force}

During this interval the population decline has affected the working population between ages 0 and $R$ but not the retired population. This phase of the population decline seems to apply quite well for the industrialized economies. It is expected that until 2010 those economies will experience an aging labor force. The year 2010 marks the time at which the baby boom generation of 1945 retires from the labor force. For the dependency ratio in this interval we can write:

\footnotetext{
${ }^{6}$ The analysis of population increase can be found in Boadway and Wildasin (1989). Their analysis contains, however, a number of errors; therefore I will elaborate and correct their analysis.

${ }^{7}$ International migration involves a number of assumptions that lie somewhat outside the scope of this paper. See van Dalen (1993) for some of the issues of international migration.
} 


$$
\eta_{t}=\frac{\int_{t-T}^{t-R} e^{n s} d s}{\int_{t-R}^{t_{0}} e^{n s} d s+\int_{t_{0}}^{t} e^{n t_{0}} e^{n\left(s-t_{0}\right)} d s}
$$

or

$$
\eta_{t}=\frac{e^{n t}\left(e^{-n R}-e^{-n T}\right)}{\left.e^{n t_{0}}-e^{n(t-R)+} e^{(n-n) t_{0}\left(e^{n t}\right.}-e^{n^{\prime} t_{0}}\right)\left(\frac{n}{n^{\prime}}\right)}
$$

In order to see how the dependency ratio changes over time, we need to derive the growth rate of the dependency ratio. If we denote the denominator of Equations 8 and 9 as $D$, and we differentiate the dependency ratio with respect to time, we obtain the following differential equation:

$$
\dot{\eta}_{t}=\frac{\eta_{t}}{D}\left(n-n^{\prime}\right)\left(\frac{n}{n^{\prime}}\right) e^{n_{0}}\left\{e^{r^{r\left(t-t_{0}\right)}}-1\right\}>0
$$

As our intuition would suggest, a decline in the population growth rate would result in an increase in the dependency ratio at first. The speed with which the increase in the dependency ratio accelerates can also be determined if we differentiate Equation 10 again with respect to time:

$$
\begin{aligned}
\ddot{\eta}_{t}= & \frac{\dot{\eta}_{t}}{D}\left(e^{n t} e^{(n-n) t_{0}}\left[\frac{n\left(n-2 n^{\prime}\right)}{n^{\prime}}\right]+e^{n(t-R)}-\left(n-n^{\prime}\right)\left(\frac{n}{n^{\prime}}\right) e^{n t_{0}}\right) \\
& +\frac{\eta_{t}\left(n-n^{\prime}\right) n e^{n t_{0}} e^{\left.n^{\prime\left(t-t_{0}\right.}\right)}}{D}
\end{aligned}
$$

where $D>0$. For a wide range of parameter settings, the speed with which the dependency ratio increases will at first be positive. Hence, the phenomenon of an aging labor force will become more apparent by the day.

\section{B. The Interval $t \in\left(t_{0}+R, t_{0}+T\right)$ : The Pension Boom}

Now in this interval the population decline will affect the number of retired, and as we mentioned in the previous section, this process will start around 2010. The dependency ratio will still increase, but once the smaller generations begin to retire, the speed with which the dependency ratio increases will fall. To see this, write down the dependency ratio for this interval: 


$$
\eta_{t}=\frac{\int_{t-T}^{t_{0}} e^{n s} d s+\int_{t_{0}}^{t-R} e^{n t_{0}} e^{n^{\prime\left(s-t_{0}\right)}} d s}{\int_{t-R}^{t} e^{n t_{0}} e^{n\left(s-t_{0}\right)} d s}
$$

or,

$$
\eta_{t}=\frac{\left(\frac{n^{\prime}}{n}\right)\left[e^{n t_{0}}-e^{n(t-T)}\right]+e^{\left(n-n^{\prime}\right) t_{0}}\left[e^{n^{\prime}(t-R)}-e^{n t_{0}}\right]}{e^{\left(n-n^{\prime}\right) t_{0}}\left[e^{n^{\prime \prime} t}-e^{n^{\prime}(t-R)}\right]}
$$

The following differential equation describing the evolution of the dependency ratio over time is:

$$
\dot{\eta}_{t}=\frac{n^{\prime}}{D n}\left(n^{\prime}-n\right)\left(e^{n(t-n)}-e^{n t_{0}}\right)>0
$$

The change in the increase in the dependency ratio becomes negative as the smaller generations also retire, thereby alleviating the pressure on the labor force:

$$
\ddot{\eta}_{t}=\left(\frac{n^{\prime}\left(n^{\prime}-n\right) e^{n(t-n}}{D}\right)-\frac{\dot{\eta}_{t} \dot{D}}{D}<0
$$

where: $\dot{D}=n^{\prime} e^{(n-n) t_{0}}\left[e^{n^{\prime t}}-e^{n^{\prime}(t-R)}\right]>0$.

The turning point in the speed of aging lies, therefore, at time $R$, the age of retirement. When this phase of the pension boom will end is, of course, hard to determine because the populations of industrialized countries are not affected by once-and-for-all birth-rate declines but by a gradual process of decline. Furthermore, the increase in life expectancy lengthens the transition period. Given the demographic trends in industrialized countries, one would expect this process to end between 2025 and 2050 .

\section{C. The Interval $t \in\left(t_{0}+T, \infty\right)$ : The New Steady State}

This last interval marks again a steady state. The dependency ratio is again stable, but it is permanently higher because the new (stable) population structure at the lower population growth rate, $n^{\prime}$, has aged.

In conclusion, the analysis of non-stable populations is to a certain extent straightforward. A population decline leads to an everincreasing dependency ratio, where the length of the transition is determined by the life expectancy $(T)$, the speed of aging is determined by the initial and long-run population growth rate ( $n$ and $\left.n^{\prime}\right)$, the age of retirement, and death ( $R$ and $T$, respectively). 
The previous calculations showed the bare bones of aging populations and some of the pitfalls one may be tempted to overlook. Summing up, key demographic variables like fertility and mortality are not interrelated as the theory of demographic transition suggests. Furthermore, they cannot be considered stationary (although the mortality time series seem to be stationary for the Dutch and U.K. economies for the post-Second World War period). Besides the non-stationary character of demographic development, there are mechanisms that speed up or slow down the transition from one state to another. For instance, lifetime expansion lengthens the period of transition. Early retirement does not affect the total transition period, but it does lengthen the period in which an economy has to deal with the increase in pensioners. The pitfalls one encounters in applied policy studies of aging is the failure to recognize the endogeneity ${ }^{8}$ and non-stationarity of the demographic state of a country.

There is, however, more to aging than demographic accounting. In dealing with the economic content of aging, one would like to know the economic burden of aging and not the demographic burden. In other words, one would like to know the development over time of the tax and benefit bases. A more general dependency ratio should take account of the income of the overlapping generations and the benefit levels that are generally indexed to current wage developments. Such a task implicitly demands knowledge of the development of future prices and the state of technology. In the next section we will turn to this issue.

\section{PITFALL II: EXOGENOUS FACTOR PRICES AND TECHNOLOGY}

So far the discussion has been purely demographic and not economic. Both are intimately related because the age structure of a population influences whether a nation as a whole saves or dissaves, whether one works or enjoys the leisure of retirement. The majority of studies of aging employing a partial equilibrium approach of constant factor prices and the state of technology generally give

\footnotetext{
${ }^{8}$ Someone who does recognize this relationship is the population economist Easterlin, who bases his theory and empirics of long-term cycles in fertility on individual decision making. His views therefore contrast strongly those of the mainstream population forecasters of national statistical offices. As he stated recently, "Both theory and history suggest as a serious possibility a prospective upswing in fertility" (Easterlin, 1992).
} 
an impression of the demographic impact of aging. However, the feedback on factor price formation is usually left out for reasons of intractability. As mentioned earlier, this is unfortunate, and in some cases it might give a false impression of the economic impact of aging. To some extent this state of affairs is understandable because the economic theory of endogenous technical progress is well-developed but the empirical underpinning of this theory is sadly lacking.

Despite the lack of empirical content on the theory of endogenous technology, one can still go through with the analysis and illustrate how important the interaction between aging and changing factor prices is. A simple theory that gives an insight into the economic consequences of a change in the rate of population growth is the life-cycle model of consumption and saving of households as developed by Arthur and McNicoll $(1977,1978)$. They take consumption and labor supply profiles as given and simply look how the age structure influences intergenerational welfare. The fundamental insight that Arthur and McNicoll offers is that an increase in the population growth rate need not be detrimental to average individual welfare. If the average age of consumption is higher than the average age of the labor force, consumers will enjoy the benefits of an implicit intergenerational transfer when the population growth increases. This is more or less the chain-letter or Ponzi-game argument: As long as there are new generations to service a debt, one can increase current welfare (see Weil, 1989). The intergenerational transfer effect of a population increase exceeds the capital dilution effect of population growth.

Of course, the reverse applies to the case of a population decline. Traditional neoclassical growth theory, as initiated by Robert Solow (1956), traces the negative effects of a population increase, because such an increase has to be accompanied by a proportional investment. Population growth dilutes the existing capital stock, and it is in this fashion that population growth is marked a "bad," and to this the science of economics owes its title "dismal science."

The analysis of Arthur and McNicoll can, of course, be further disaggregated to take account of the household composition and the consumption pattern of the various household members. Analysis of this type has been done by Lee and Lapkoff (1988) and Ermisch (1989). Ermisch has found that the average age of consumption in Great Britain and Japan exceeds the average age of the labor force. Assuming no productivity growth over generations, the average ages of household consumption and the labor force in Great Britain 
are 46.3 and 41.3 , respectively. If we assume a 2 -percent rate of productivity, the average ages of consumption and production are 41.7 and 38.7 , respectively. The average ages of consumption and production in Japan are higher than those of Great Britain. For instance, with a 2-percent productivity growth rate, the average age of consumption is 45.1, and average age of production is 41.0. These findings are in general agreement with those of Lee and Lapkoff (1988) for the United States. The general conclusion is that net transfers between households go from younger to older generations. This intergenerational transfer effect may, however, be dampened, if not outweighted, by the capital dilution effect. Some general calculations by Ermisch (1989) show that the capital dilution effect may indeed be stronger than the intergenerational transfer effect.

In a related but different manner, one can look at the issue of exogeneity of factor prices by looking at the historical development of real factor prices. In a small but influential paper, Henry Aaron (1966) showed the conditions under which a PAYG scheme implies a Pareto improvement for the generations concerned. The alternative method of financing social security is the capital reserve (CR) or fully funded system. The exact condition is in fact a (stationary) dynamic efficiency condition, namely $r>n+g$; that is, the economy is characterized by underinvestment. Under this condition no generation can improve its welfare by investing in the PAYG-financed social security system without harming the welfare position of another generation. The intuition behind the Aaron result is straightforward: Both systems, CR and PAYG, are assets with their own rate of return. The rate of return of the CR system is the expected real interest rate, and the rate of return of the PAYG system is the sum of the population growth rate and, if the benefit levels are indexed to real wage growth, the real wage growth rate. Under conditions of uncertainty with respect to the inflation rate, interest rates, and nominal wages, one has to look at how these key variables will develop over time. The transversality condition on government debt requires a zero limit of discounted future government debt (see Bohn, 1991). Analysis of historical development might provide some hints about how large the differences between the key rates of returns are. Figure 4 shows the development of the ex ante real interest rate together with the population growth rate for the U.K. economy over the period 1728-1990. The expected real interest rate 


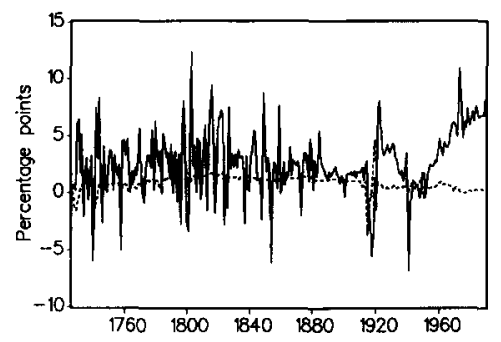

Figure 4. Expected real interest rate and population growth.

Expected real interest rate .... Population growth rate

is defined as the nominal interest rate minus the expected inflation rate. ${ }^{9}$

The irony of this figure is that ever since the Beveridge welfare state was introduced after the Second World War the population growth rate has never exceeded the real interest rate. However, a more more just picture would be to illustrate the divergence between the expected real interest rate on the one hand and the sum of the expected real wage rate and population growth rate on the other hand. This is in fact the Aaron condition. Figure 5 shows this condition for the period 1803-1990 together with the line expressing equality of the two rates of return, namely the interest rate on the one hand and the real wage growth rate and population growth rate on the other hand. As one can see, an unambiguous choice is no longer possible on the basis of these parameters. If one wants to decide on the method of finance, one has to take account of the uncertainty surrounding the key determinants of the capital reserve and the PAYG system.

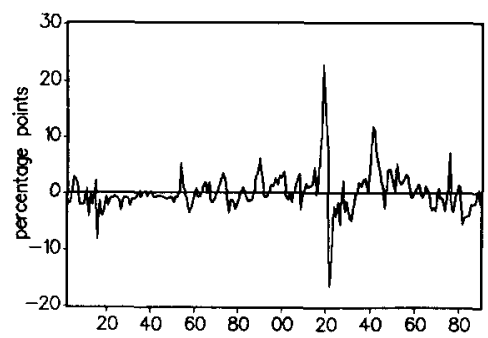

Figure 5. Aaron condition $(r-n-g), 1800-1990$.

\footnotetext{
${ }^{9}$ The expected inflation rate is modeled as an $\operatorname{ARMA}(1,1)$ process.
} 
Finally, we have to pay attention that a pitfall that lies at the heart of economic theory, namely the assumption of perfect competition. Mainstream macroeconomists assume that markets are complete and that the individual agents act in perfect competition with each other. Because agents act atomistically, they take prices as given. They can only influence prices in an indirect manner, namely through aggregate market transactions. If one discards this simplifying assumption and replaces it by monopolistic behavior, one might come closer to a more realistic model of the economy, namely one in which the market power of pension funds is a real issue, like in some industrialized countries (the United Kingdom and the Netherlands). With respect to aging economies, the issue is relevant because private pension funds and insurance companies are gathering clout on the capital market where they have become the dominant supplier of capital. As shown in van Dalen and van Praag (1993), monopolistic behavior of pension funds is detrimental to consumer welfare because pension funds drive up the real interest rate and consequently lower real wages by acting strategically on the capital market. The danger of dominant pension funds is an issue easily overlooked, but it will gain weight as the rate of savings, contractural and voluntary, increases.

\section{PITFALL III: TIME INCONSISTENT PAYG SCHEMES}

A point that is often neglected in the formulation of economic policy is the question whether optimal plans made today are still optimal tomorrow. Ever since the seminal paper by Kydland and Prescott (1977) on the time inconsistency of optimal plans, it has become apparent that one has to be more careful in formulating economic policy. One can fall easily prone to the temptations of reneging on optimal policies announced yesterday. Social security is a case in point because it appears optimal from the point of view of the current constituency but as time passes one may find that a majority is in favor of defaulting on social security obligations. In short, the time-inconsistency argument of economic policy is simply an argument that tells you, "Beware of presidents that utter: Read my lips, No New Taxes!" A policy that is proposed at the beginning of an administration may look optimal with the perspective of someone who is looking at issues from time $t$. But one period later, the economy will have changed on account of reactions of consumers and producers to the proposed policy. However, a government that starts to recalculate policy as from time $t+1 \mathrm{on}$, will be tempted to change its policy and start to tax economic behavior that ex ante was variable and ex post is fixed. In other words, a government suddenly becomes aware of a tax base that will make 
the welfare loss of taxation smaller. The time-inconsistency problem that lies behind the modern-day welfare state can best be discussed in general terms (compare Chari, Kehoe, and Prescott, 1989) and compare the two systems under conditions of commitment and the absence of commitment.

The basic difference between capital reserve (CR) and PAYG is that the first system is intragenerationally and intergenerationally neutral, whereas the second system is by definition not so. The intention of PAYG is to redistribute national income among heterogenous agents. The government that intends to deal with social security matters by means of the finance method PAYG implicitly defines its policy in terms of aggregate average allocations instead of the sum of individual allocations. To show the divergence in policy outcomes, we define the objective function of individual agents as:

$$
U^{i}(x, \tau)=U\left(x_{i}, \beta \bar{x}, \tau\right)
$$

where $\bar{x}=\sum_{i=1}^{n}(1 / n) x_{i}$ denotes the aggregate per capita allocations, and $\beta$ is a parameter that defines the mixture of PAYG and CR. Under complete PAYG coverage $\beta=1$, and under full $C R$ coverage $\beta=0$. For $0<\beta \leq 1$, the individual agent $i$ indirectly takes account of the allocations of other agents. By assumption, agents take decisions in a competitive manner, and therefore the aggregate allocation, $\bar{x}$, and the policy $\tau$, are taken as given. Under conditions of commitment, the government chooses a policy $\tau$, and then given this policy rule, private agents simultaneously choose their actions, $x$. Each agent $i$, faced with policy $\tau$ and taking as given the actions of all other agents, $x_{-i}=\left(x_{1}, \ldots, x_{i-1}, x_{i+1}\right.$, $\ldots, x_{n}$ ) maximizes Equation 16 with respect to $x_{i}$, yielding the interior first-order condition:

$$
\frac{\partial U}{\partial x_{i}}=0 \text { for all } i
$$

Assume that for each $\tau$ there is a unique equilibrium $x$ and the resulting outcome function $X(\tau)$ is differentiable. The objective function of the government in charge of the social security system is:

$$
S(x, \tau)=\sum_{i=1}^{n} U^{i}\left[(1-\beta) x_{i}, \beta \bar{x}, \tau\right]
$$

The policy rule, $T$, used by the government under conditions of a 
complete PAYG system is restricted to depend only on the aggregate allocation, $\bar{x}$. The first-order conditions for the government designing a social security system are for $0 \leq \beta \leq 1$ :

$$
\sum_{i=1}^{n}(1-\beta) \frac{\partial U^{i}}{\partial x_{i}} \frac{\partial X}{\partial \tau}+\beta \frac{\partial U^{i}}{\partial \bar{X}} \frac{\partial \bar{X}}{\partial \tau}+\frac{\partial U^{i}}{\partial \tau}=0
$$

\section{Definition 1: A Commitment Equilibrium}

An equilibrium with commitment is a policy $\tau^{*}$ and an outcome function $X($.$) that satisfy:$

(1) Maximization for society. Given $X($.$) , the policy \tau^{*}$ solves society's maximization problem (Equation 18).

(2) Private equilibrium. For each $\tau$, the outcome $X(\tau)$ is an equilibrium for individual agents.

Without commitment, the equilibrium allocation can diverge considerably from the commitment equilibrium. The reason why this is so can be traced back to the setting without a commitment technology. Individual agents first choose a vector $x$, and then government chooses a policy, $\tau$. Given the individual and aggregate allocations, the problem faced by the government is to maximize Equation 18 with espect to $\tau$, giving rise to the first-order condition:

$$
\sum_{i=1}^{n} \frac{\partial U^{i}}{\partial \tau}=0
$$

Assume that similar to the outcome function $X($.$) for each vector$ $x$, the policy $\tau$ defined by Equation 20 is unique and the policy rule $T\left[(1-\beta) x_{i}, \beta \bar{x}\right]$ is differentiable. In the no-commitment equilibrium each individual agent takes the policy rule $T($.$) and the decisions$ of other agents $x_{-i}$ as given and maximizes the following function with respect to $x_{i}$.

$$
U\left[x_{i}, T\left(x_{i}(1-\beta), \beta \bar{x}\right)\right]
$$

The first-order condition for each agent $i$ is:

$$
\frac{\partial U}{\partial x_{i}}+\frac{\partial U}{\partial \tau} \frac{\partial T}{\partial x_{i}}(1-\beta)=0
$$

In this formula we let each agent take account of the effect of his action on the government's policy rule. Of course, when the number of agents is large this effect will become small and in the limit zero. 


\section{Definition 2: A No-Commitment Equilibrium}

An equilibrium without commitment is a vector of private decisions $x^{*}$ and a policy rule $T($.$) that satisfy:$

(1) Private equilibrium. Given $x_{-1}^{*}$ and $T(),. x^{*}$ solves Equation 21 for every $i$.

(2) Maximization for society. For any $x$, the policy $T($.$) solves$ Equation 20.

We are now able to compare the two equilibria with and without commitment. The equilibrium with commitment is completely characterized by Equations 17 and 19, yielding for all agents $i$ :

$$
\sum_{i=1}^{n} \beta \frac{\partial U^{i}}{\partial \bar{x}} \frac{\partial \bar{X}}{\partial \tau}+\frac{\partial U^{i}}{\partial \tau}=0, \frac{\partial U^{i}}{\partial x_{i}}=0
$$

Without commitment, the equilibrium is characterized by Equations 20 and 22 yielding:

$$
\frac{\partial U^{i}}{\partial \tau}=0, \frac{\partial U^{i}}{\partial x_{i}}=0
$$

One of the propositions one can immediately derive from Conditions 23 and 24 is that if $\beta=0$ (i.e., the CR case) there is no time-inconsistency problem. This result depends on the fact that under those conditions the individual and the state have the same objective function. If, however, an economy is characterized by a mixture of systems or full PAYG coverage (i.e., $0<\beta \leq 1$ ), the two equilibria diverge because the objective function of the state depends on aggregate per capita allocations, thereby causing a conflict of interest among agents. With a commitment technology, the externality of the aggregate allocation is taken into account, whereas under conditions of free discretion the conflict among agents is allowed to develop freely. In general, the welfare of consumers under conditions of the discretionary policy is less than the welfare under conditions of a commitment technology.

In conclusion, the general intuition behind the problem of time consistency revolves around the more down-to-earth notion of credibility: Does one believe the government's intentions? The pitfall one encounters in numerous policy studies on aging is the absence of any consideration for the credibility of proposed solutions to the public financial problems tied to an aging population. 


\section{PITFALL IV: IMPLICIT INTERGENERATIONAL TRANSFERS}

One of the missing links in modeling aging economies is the development of the productivity of the individual employee over his or her lifetime. Knowledge about how labor is rewarded over its lifetime is quite abundant: In general, labor income over the working lifetime has an inverted U shape. ${ }^{10}$ However, the relationship between the individual's relative wage and his or her productivity seems to be weak on a temporal basis (see Bishop, 1987).

In general, wages seem to grow faster than productivity over the individual's life cycle. Firms finance this lifetime contract by equating the discounted sum of the individual's wage income with the discounted sum of the individual's productivity. The delayedpayment contract introduces a form of fixed costs into the employment relationship. These fixed costs lead firms to hire primarily younger workers, who can start at the bottom of the firm's ladder. Empirical evidence by Hutchens (1986) shows that firms do employ older workers who are serving out the last years of their lifetime contract, but they tend not to hire new older workers.

The number of explanations that have been put forward to explain the phenomenon of delayed payment is quite diverse: The divergent wage-productivity nexus is used as an instrument (1) to discourage shirking and malfeasance (Lazear, 1979), (2) to facilitate firm-specific training, (3) to cushion the adverse effects of variations in productivity, and (4) to avoid adverse selection, or (5) to facilitate a rising lifetime-consumption profile (Frank and Hutchens, 1993).

Whatever the reason may be behind this wage-productivity construction, one immediate deduction seems relevant for discussing the economic consequences of aging, namely: Within organizations, intergenerational transfers are flowing from young workers to older workers. In other words, an implicit PAYG scheme is part and parcel of long-term job offers. This scheme is financed by paying younger workers less than their marginal productivity and older workers more than their worth in terms of productivity. The turning point in this schedule lies in the age bracket of 45 and 50 years (see Eggink et al., 1993). Empirical evidence by Kotlikoff and Gokhale (1992) shows that productivity and wage income move in line for positions or functions that are tied to explicit productivity goals, like sales persons. Other types of personnel are more difficult

\footnotetext{
${ }^{10}$ See Murphy and Welch (1990).
} 
to monitor and are paid in line with their expected lifetime productivity. With respect to the future of aging populations there are three inherent weak points of this reward system, points that are at some instances already apparent in OECD countries (see OECD, 1992).

The first difficulty has to do with credibility of the sustainability of this implicit labor contract. The implicit contract ("the invisible handshake") stipulates that the older worker receives an income in excess of his marginal productivity; employers did not keep their promise and made the older workers leave the firm (OECD, 1992). By means of this breach of contract, the employer could improve the profitability of the firm by making the age structure of the firm younger so that the average pay is below the average productivity of the firm's employee.

The second difficulty is connected with the indirect effect that the induced early retirement from the labor force has on the sustainability of PAYG public-pension schemes. With an eligible retirement age for a public pension that exceeds the early retirement age, the number of beneficiaries does not change, but the social security premium base does. Subsequently the premium will rise and, if conditions of dynamic efficiency prevail, reinforce the early retirement trend. In short, the implicit private PAYG scheme inside organizations and the public social security PAYG scheme will reinforce each other when populations age.

The third difficulty is connected to the second one because the majority of private pension schemes is benefit-defined; that is, pension contracts are defined in terms of the benefits, and pension premiums are adjusted accordingly. Furthermore, the benefit is mostly stated as a replacement rate (usually $60 \%$ and $70 \%$ ) of the final pay one receives in working life. The "final pay" arrangement is, however, implicitly financed in a PAYG manner. Employees with a flat lifetime wage profile pay for the pensions of employees with a steep lifetime wage profile. Again, as Section 4 showed, every PAYG scheme is bound to be time-inconsistent and so is the "final pay" arrangement.

\section{SUMMARY}

Aging has a pervasive influence on economies. Not only the absolute size of population groups matters, but also the indirect effect of aging populations on relative prices of goods and production factors has to be taken into account if one wants to assess the 
economic consequences of aging. A number of causes have given rise to the phenomenon of aging, a fall in the fertility level and a rise in the average life expectancy being two of the most prominent causes. The predictability of those two variables has changed over time. The uncertainty surrounding the mortality rate has decreased over time, whereas the uncertainty of the fertility rate has not changed significantly. A thorough understanding of fertility remains one of the tasks of economists if they want to assess the economic consequences of future demographic developments.

In this paper I have provided for the reader a number of pitfalls one may encounter while analyzing or reading about future developments in economic demography. The stability and constancy of population growth may provide economists the access to analytically tractable models, but it may provide the reader a false picture of what lies ahead. Furthermore, statistical tests of the so-called theory of demographic transition do not reveal for the case of England and the Netherlands that this theory has some statistical significance: The death rate and birth rate are not cointegrated. A second pitfall is the constancy of relative-factor prices and technology. Especially with the choice of a method of payment for social security programs, this pitfall may have considerable consequences. Economic history shows how important the uncertainty of relativefactor prices is for the macroeconomic analysis of social security finance. The time-inconsistency of PAYG schemes of social security schemes and implicit contracts of delayed payments constitute pitfalls number three and four, respectively. The PAYG schedule is not credible because it introduces a conflict of interest between the government and the citizen that will only coincide if the government employs the finance method of capital reserve. Another alternative is that the citizens act collectively and take into account the externality in decision making that lies at the heart of the theory of time-inconsistency (see Rodrik, 1993).

A major pitfall not discussed in this paper concerns the pitfall one encounters when examining the ethical side of aging societies, a pitfall that lies somewhat outside the scope of economic theory. The theory of public economies takes as a point of departure the two fundamental theorems of welfare economics. The first of these states that a competitive equilibrium is Pareto-efficient. The second states that a centrally designed Pareto-efficient allocation can be achieved as a competitive equilibrium if prices are set appropriately and lump-sum incomes are allocated so that each individual can buy the consumption bundle given in the allocation at the prices 
that will prevail. However, the possibility may be raised that even though one finds oneself in a situation that is called Pareto-efficient, this allocation may still be the worst of all possible worlds. One would like to go beyond the Pareto-efficiency criterion and consider different "states of the world" resulting from different economic policies. The Pareto principle eschews interpersonal comparisons of utility, and thus the principle cannot be used for comparing policies that generate gains for one group and losses to other groups. In evaluating the welfare consequences of aging or demographic change in general, one has to invoke a social welfare criterion to make the evaluation explicit. We have deleted a discussion on this pitfall because it lies outside the classical scope of economics and because a more-thorough discussion of this topic would involve an introductory exposition on ethics, an exposition that would be hampered by the limitations of space. ${ }^{11}$

The pitfalls mentioned above make the economic analysis of aging a challenging subject. The main lesson one should remember is to remain suspicious whenever one hears an economist or a policymaker present policy measures or guidelines that "solve the aging problem." One should always try to make one's own evaluation of the economic implications of aging. Too much reliance on economic experts may induce a person to make exclamations similar in vigor to the outburst made by the U.S. President Warren G. Harding (1920-24) when he talked to his secretary after a hearing on matters of public finance:

“John, I can't make a damn thing out of this tax problem. I listen to one side and they seem right, and then -God! - I talk to the other side, and they seem just as right. I know somewhere there is a book that will give me the truth, but hell, I couldn't read the book. I know somewhere there is an economist who knows the truth, but I don't know where to find him and haven't the sense to know and trust him when I find him. God! what a job!"

The economic policy analysis of aging is indeed a "hell of a job." However, I venture to state that the four pitfalls summed up in this paper may improve the job of the economist dealing with and analyzing the economic consequences of aging.

\footnotetext{
${ }^{11}$ Dasgupta (1988) discusses some of the ethical problems of population economics. In a more down-to-earth manner Blanchet and Kessler (1991) show how the choice of social welfare parameters can drastically change policy conclusions with respect to pension finance in an aging society.
} 


\section{REFERENCES}

Aaron, H.J. (1966) The Social Insurance Paradox, Canadian Journal of Economics and Political Science 32:371-374.

Alogoskoufis, G., and van der Ploeg, F. (1990) Endogenous Growth and Overlapping Generations, CentER Discussion Paper No. 9072, Tilburg.

Arthur, W.B., and McNicoll, G. (1977) Optimal Time Paths with Age-Dependence: A Theory of Population Policy, Review of Economic Studies 44:111-123.

Arthur, W.B., and McNicoll, G. (1978) Samuelson, Population, and Intergenerational Transfers, International Economic Review 19:241-246.

Auerbach, A.J., Kotlikoff, L.J., Hagemann, R.P., and Nicoletti, G. (1989) The Dynamics of an Ageing Population: The Case of Four OECD Countries. Working Paper No. 62, OECD, Paris.

Bishop, J. (1987) The Recognition and Reward of Employee Performance, Journal of Labor Economics 5:S36-S56.

Blanchet, D., and Kessler, D. (1991) Optimal Pension Funding with Demographic Instability and Endogenous Returns on Investment, Journal of Population Economics 4:137154.

Boadway, R., and Wildasin, D. (1989) Voting Models of Social Security Determination. In The Political Economy of Social Security (B.A. Gustafsson and N. Anders Klevmarken, Eds.). Amsterdam: North-Holland.

Bohn, H. (1991) The Sustainability of Budget Deficits in a Stochastic Economy. Mimeo, University of Pennsylvania, Philadelphia.

Chari, V.V., Kehoe, P.J., and Prescott, E.C. (1989) Time Consistency and Policy. In Modern Business Cycle Theory (R.J. Barro, Ed.). Oxford: Basil Blackwell.

Coale, A.J. (1989) Demographic Transition. In The New Palgrave. (J. Eatwell, M. Milgate, and P. Newman, Eds.). London: MacMillan.

Colander, D. (1992) Retrospectives: The Lost Art of Economics, Journal of Economic Perspectives 6:191-198.

Cutler, D.M., Poterba, J.M., Sheiner, L.M., and Summers, L.H. (1990) An Aging Society: Opportunity or Challenge? Brookings Papers on Economic Activity 1:1-74.

Dasgupta, P. (1988) Lives and Well-Being, Social Choice and Welfare 5:103-126

Easterlin, R.A. (1992) Should Economists Be Dependent on Official Fertility Projections? Challenge July-August:51-53.

Eggink, E., Hop, J.P., and van Praag, B.M.S. (1993) A Systematic Approach to the Labor Market with the Household as Unit of Observation, Journal of Applied Econometrics. In press.

Ermisch, J. (1989) Intergenerational Transfers in Industrialized Countries, Effects of Age Distribution and Economic Institutions, Journal of Population Economics 1:269284.

Frank, R.H., and Hutchens, R.M. (1993) Wages, Seniority and the Demand for Rising Consumption Profiles, Journal of Economic Behavior and Organization 21:251-276.

Hagemann, R.P., and Nicoletti, G. (1989) Ageing Populations: Economic Effects and Implications for Public Finance, OECD Economic Studies, No. 12, Paris.

Halter, W.A., and Hemming, R. (1987) The Impact of Demographic Change on Social Security Financing, IMF Staff Papers 34:471-502.

Heller, P.S., Hemming, R., and Kohnert, P.W. (1986) Aging and Social Expenditures in the Major Industrial Countries, 1980-2025, Occasional Paper No. 47. Washington: International Monetary Fund.

Henkens, K., and Siegers, J. (1991) The Decision to Retire: The Case of Dutch Men Aged 50-64, European Journal of Population 7:231-249. 
Hutchens, R. M. (1986) Delayed Payment Contracts and a Firm's Propensity to Hire Older Workers, Journal of Labor Economics 4:439-457.

Kotlikoff, L.J., and Gokhale, J. (1992) Estimating a Firm's Age-Productivity Profile Using the Present Value of Workers' Earnings, Quarterly Journal of Economics 107:12151242.

Kydland, F.E., and Prescott, E.C. (1977) Rules Rather Than Discretion: The Inconsistency of Optimal Plans, Journal of Political Economy 85:473-492.

Lazear, E.P. (1979) Why Is there Mandatory Retirement? Journal of Political Economy 87:1261-1284.

Lazear, E.P. (1986) Retirement from the Labor Force. In Handbook of Labor Economics, Vol. I (O. Ashenfelter and R. Layard, Eds.). Amsterdam: North-Holland.

Lee, R.D., and Lapkoff, S. (1988) Intergenerational Flows of Time and Goods: Consequences of Slowing Population Growth, Journal of Political Economy 96:618-651.

Masson, P.R., and Tryon, R.W. (1990) Macroeconomic Effects of Projected Population Aging in Industrial Countries, IMF Staff Papers 37: 453-485.

Merton, R. (1975) An Asymptotic Theory of Growth Under Uncertainty, Review of Economic Studies 42:375-393.

Murphy, K. M., and Welch, F. (1990) Empirical Age-Earning Profiles, Journal of Labor Economics 8:202-229.

OECD (1988) Ageing Populations: The Social Policy Implications, Demographic Change and Public Policy Series, No. 1, Paris.

OECD (1992) Labour Market Participation and Retirement of Older Workers, Employment Outlook, July 1992, OECD, Paris.

Rodrik, D. (1993) Redistributive Taxation without Excess Burden, Economics and Politics 5:53-60.

Said, S.E., and Dickey, D.A. (1984) Testing for Unit Roots in Autoregressive-Moving Average Models of Unknown Order, Biometrika 71:599-607.

Solow, R. (1956) A Contribution to the Theory of Economic Growth, Quarterly Journal of Economics 70:65-94.

Stewart, J. (1991) Econometrics. New York: Philip Allan.

van Dalen, H.P. (1992) Economic Policy in a Demographically Divided World. Berlin: Springer Verlag.

van Dalen, H.P. (1993) International Migration, Economic Policy and Human Capital Accumulation, Economic Modelling 10:417-429.

van Dalen, H.P., and van Praag, B.M.S. (1993) Public Pensions, Market Power, and Intergenerational Confidence, Public Finance/Finances Publiques. 48:16-28.

van Imhoff, E. (1989) Optimal Economic Growth and Non-Stable Population, Berlin: Springer Verlag.

Weil, P. (1989) Overlapping Families of Infinitely-Lived Agents, Journal of Public Economics 38:183-198. 